\title{
HEALTHCARE SERVICES CONSUMER BEHAVIOR IN THE LIGHT OF SOCIAL NORMS INFLUENCE
}

\author{
Daniel Adrian GÂRDAN, \\ Spiru Haret University \\ postdoctoral student, Institute of World Economy-Romanian Academy \\ E-mail: danielgardan@yahoo.com \\ Iuliana Petronela GÂRDAN (GEANGU) \\ Spiru Haret University \\ postdoctoral student, Institute of National Economy-Romanian Academy \\ E-mail: geangupetronela@yahoo.com
}

\begin{abstract}
Healthcare services consumers' behavior represents an multidimensional concept, that implies the cumulative effects of different factors. The process of consumption is very different and complex in the case of healthcare services due to the nature of the needs and consumption motivations on one hand and because of the complexity of the services itself on the other hand. Amongst the factors that are influencing the consumer's behaviour, the social ones represent a particular type. In the case of healthcare services this is because the social interactions of the patients can contribute to their own perception regarding the post consumption satisfaction, or can influence the buying decision in the first place. The influence of social factors can be analysed on multiple layers - from the effect of the affiliation and adhesion groups to the effect of social norms and regulations.
\end{abstract}

Keywords: social norms, affiliation groups, healthcare services, consumer behavior

JEL Classification: $\mathrm{I}_{12}, \mathrm{M}_{31}$

\section{Introduction}

Social interactions are referring to generative relations that are capable to induce changes at the level of perceptions and through these changes at the level of consumer's actions.

The analysis of consumption behavior or buying behavior can't be done without taking account of the fact that peoples find themselves all the time in a evolutionary, historical and institutional context. From this point of view interactions between individuals become very important.

The consumer behavior is influenced by a variety of factors both endogenous and exogenous. This duality of the endogenous and exogenous influences upon the consumer's behavior create the picture that bring into evidence the evolution of the social structures itself from the dawn of the civilization until present time. The 
human being cannot escape from the social framework present into his life from childhood. At his turn, this social framework with all its institutions, social groups etc, represents the effect of human activities, of choices and consumption acts which individuals have usually.

From the healthcare services consumption perspective, these social interactions attain new valences given by the specific of the healthcare services and the needs which are behind consumption motivations.

The choices made by the healthcare services consumers, the behavior that is related with influence groups are changing and contribute in the same time to the evolution of medical system, of institutions that are regulating the provision of these services. Thus, on a long run, the consumption processes will self-regulate and the efficiency of provisions will rise towards a better serving of the social interest. All the spectacular transformations at the level of nowadays medical technology, last minute methods and treatments, are proving that the social needs conjugated with healthcare individual needs have been shaped this field and are continuing to shape it.

\section{Social norms and their importance in the context of social factors influence}

Norms, in the most general sense are presenting as rules, pre-established sets of decisions seeing as responses to the manifestation of social mechanisms. Thus a fist definition of social norms points out that these are representing rules which prescribe behaviors expected by a community or an institution. (Popescu-Neveanu, P., 1978, p. 481)

The normative level presuppose the existence and manifestation of some rules or formal norms, being as juridical nature or having a moral substrate and also a series of informal constrains, developed along the society evolution and of social inter-relations. The norms may have a mandatory character as it is the case for juridical norms, or of social constraint as in the case of moral norms.

The social norms that are general appealing - the social norms that exists in a field or another are credited with a high level of influence over the individuals' behavior. The problem is, in what extent the social norms that are characteristic for a minority of consumers, eventually for a social group are as much as striking referring to the effect that they can determine upon the consumers behavior.

Thus in the social plan, each individual will assume a certain role, that is suited to the status that he has. Thus during its development and maturation, the individual will form a certain attitude regarding the roles and statues that he can have at a social level.

His behavior, his personality will be reported to the social system of norms and values. This system represents a mixture of cultural elements, anthropologic ones, representative for the human civilization. The norms although they have a constraint character, are still permissive in the same time, trying to develop a equilibrium between the needs expressed by the individuals and the social 
requirements that are characteristics for a certain level of development of the society in a particular moment in time.

The relations that are establishing between the juridical norms and the social ones are presenting equivalence reports, without any kind of a "subordination". They are representing different aspects from the formal point of view regarding the same reality - rules that are important for the proper functioning of the society.

\section{The consumer behavior and the pressure of social groups}

Individuals may define themselves as being members of a social predestined category. They can learn or elaborate stereotypical norms for this category. Also they receive a confirmation that certain behavior modalities based on these norms are attributes specific to the defined social category (group), such as some learned behaviors are expected or wanted and utilized as such in order to make the differentiation between different social categories or belonging groups (Neculau, A. (coord.), 1996, p. 370)

The individuals will become more and more integrated into the group, and their behavior is becoming more and more similar with the other members.

The group can be defined as being a human ensemble that has members that are having interactions ruled by some pre-established norms.

We can find, in the relevant literature different types of social groups taking into account the type of interactions between the individual member and the whole group.

From a marketing perspective, within social groups it can be outlined the adhesion groups and reference groups (Armstrong, G., \& Kotler, P., 2012). The adhesion group is represented by the group that has a direct influence and an individual that can be a part of it, will transform himself from the point of view of all aspects regarding his social development at a particular moment in time family, the professional team, political unit, local community etc.

The reference group, according to Hyman can be defined as a group of which an individual will report himself as an actual active member or a future one. (Hyman, H.H., 1960, p. 383-396). The reference group will influence or will determine the behaviors and attitudes of those that are identifying with it, in a differentiated way, certain persons can be a reference group in a particular field and other persons in another field.

Thereby, an individual can be part simultaneously from more different reference groups, taking account his interests and the complexity of social life involvement.

Each reference group will be determinative for certain values, attitudes etc, specific elements that will leave their mark upon the behavior of its members.

Taking account of the typology of individuals, the period of time that has passed from the first identification with the group and the relations within the group, we can see a greater or lesser influence of the social norms associated with the group upon the actual buying or consumption behavior. 
Thus, scholars have determined that we can have "social" type buyers or "solitary" type buyer.

The social type buyer will have as a tendency a behavior centered on relationship with the other members and as a result they may be able to buy more products. (Anić, I.D., \& Radas, S., 2006, p. 733). Starting from the same type of mechanism it can be observed a different type of behavior in case of couples that have babies compared with the ones that doesn't have.

One of the most well-known types of membership group is represented by the family. The family will have a very complex influence upon the consumer's behavior from the point of view of different aspects: the life stage of the family, its cultural type, etc. From the point of view of the life cycle stage, the quality and the dynamic of the interactions between individual and the family it can be very different from stage to stage (Wells, W.D., \& Gubar, G., 1966, p. 355-363). The cultural type of the family is a factor that also contributes to the behavior of its members and the relationship between them. The analysis reveals a patriarchal type family on one hand and an egalitarian type family on the other. Each cultural type is developing its own kind of relationship between members, with social roles that have different characteristics and positions. We can enumerate: initiator, influencer, decider, buyer or user (Cant, M.C., Strydom, J.W., Jooste, C.J., \& Du Plessis, P.J., 2009, p. 87).

As a conclusion we may state that individuals tend to adopt life styles that are common with their social group and modify them according to some standards, as much as they grew older. Also they will develop a kind of pattern starting from the norms incorporated within their behavior and this will lead to the possibility of consumption optimization (Starr, M.A., 2009, p. 25-49).

\section{Practical implications for dental healthcare services consumer behavior}

The influence of social factors upon the dental healthcare services consumer behavior is undoubtedly obvious, because a healthcare type service has a complex consumption motivation behind and deep emotional involvement of the consumers.

Different research has revealed that there are notable differences between consumption habits of women to men or married people to unmarried or separated people. Thus the people that are engaged in a more fruitful social life (women or married people) have a greater consumption volume than the persons that are single or do not imply themselves in multiple social relationships (Tchicaya, A., \& Lorentz, N., 2014, p 1-14).

One of the author's previous qualitative research made on dental medics at the level of Bucharest town has pointed out also information's regarding the perception of doctors upon the influence of social factors.

Thus the doctors have appreciated that the influence of the family as a social group is prevalent, many of the respondents considered that more female patients have a greater impact upon their husbands regarding the dental healthcare services consumption than the opposite. Also doctors believe that apart from the influence of husbands or spouses, there is an influence from an opinion leader from a 
particular group or from a person emotionally closer to the patients. Another interesting topic was related to the fact that persons who have had very bad dental diseases or even surgical interventions are exposed to the negative image from the others and have problems with the social integration at the workplace. This shows that the construction of the self-image of individuals is based on a great extent on the perception and image of the others about them, and the social capability of a person to integrate within different groups is depending on the way in which that person is capable to find equilibrium between the two - internal and external perceptions.

Another authors" quantitative web based research suggested that the pressure of social groups upon the consumers behavior is nuanced because respondents have declared in a lesser extent to renounce to a medical dental treatment just in order to be in line with the friends or family members opinions. This shows that, even if the influence from social groups exists, a special situation can be met when the power of self-motivations is very high, and these motivations are related to the health status of the individuals.

It can be pointed out, that also at the level of this quantitative research, even if there was a measurement of the patient's opinions, these are similar with the ones of the doctors related with importance of self-image and the others persons perceptions.

Consumption motivations related to dental healthcare services may have as a basis a complex body of thought related to the self-image perceptions and the social status importance. There are different types of dental provisions that are complementary to the basic interventions that have merely a medical - clinical purpose. We can refer to the dental aesthetic procedures, rhinestones fitting etc., procedures that are intended to fulfill other type of needs than the normal ones. We talk about the self -image construction or reconstruction, and the display of a certain status.

This type of consumption is a Veblevian type, directed to the social status enforcement through a conspicuous consumption.

\section{ACKNOWLEDGMENT}

This paper has been financially supported within the project entitled "Horizon 2020 - Doctoral and Postdoctoral Studies: Promoting the National Interest through Excellence, Competitiveness and Responsibility in the Field of Romanian Fundamental and Applied Scientific Research", contract number POSDRU/159/1.5/S/140106. This project is co-financed by European Social Fund through Sectorial Operational Programme for Human Resources Development 2007-2013. Investing in people! 


\section{References}

- Anić, I.D., \& Radas, S. (2006). "The impact of situational factors on purchasing outcomes in the Croatian hypermarket retailer", Ekonomski pregled, 57(11), p. 730-752.

- Armstrong, G., \& Kotler, P. (2012), Marketing: An Introduction (11 ${ }^{\text {th }}$ Edition), New Jersey: Prentice Hall.

- Cant, M.C., Strydom, J.W., Jooste, C.J., \& Du Plessis, P.J. (2009). Marketing management, Fifth edition, Cape Town: Juta Academic.

- Hyman, H.H. (1960). "Reflections on reference groups", Public Opinion Quarterly, 24(3), p. 383-396.

- Neculau, A. (coord.) (1996). Psihologie socială. Aspecte contemporane, Iaşi: Polirom.

- Popescu-Neveanu, P. (1978). Dicţionar de psihologie, Bucureşti: Editura Albatros.

- Starr M.A. (2009). "Lifestyle conformity and lifecycle saving: a Veblenian perspective", Cambridge Journal of Economics, 33(1), p. 25-49.

- Tchicaya, A., \& Lorentz, N. (2014). "Socioeconomic inequalities in the non-use of dental care in Europe", International Journal for Equity in Health, 13(7), p. 1-14, http://www.biomedcentral.com/content/pdf/1475-9276-13-7.pdf

- Wells, W.D., \& Gubar, G. (1966). "Life cycle concept in marketing research", Journal of Marketing Research, 3(4), p. 355-363. 